\title{
Isolated paraspinal muscle cysticercosis diagnosed on ultrasonography in a young patient presenting as low back ache
}

\section{Sheikh Afaq, Amit Mittal' Rumana Farooq $\mathbf{M i r}^{2}$}

Departments of Medicine, ${ }^{1}$ Radiodiagnosis, ${ }^{2}$ Microbiology, M.M. Institute of Medical Sciences and Research, Mullana, Ambala, Haryana, India

Address for the Correspondence: Dr. Sheikh Afaq, Department of Medicine, M.M. Institute of Medical Sciences and Research, Mullana, Ambala - 133 207, Haryana, India.

E-mail: sheikhafaq6@gmail.com

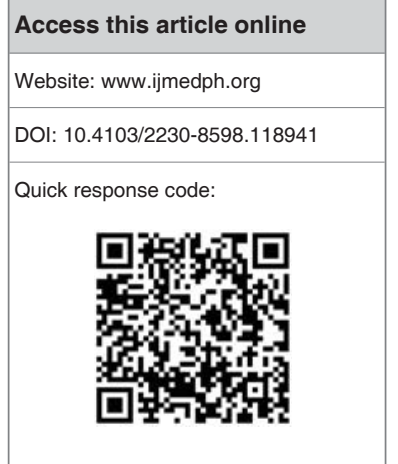

Cysticercosis is a grave helminth infection caused by the larval stage of a Taenia solium, it is commonly seen as cysts in various body tissues. Usually the patients with cysticercosis are asymptomatic, but in symptomatic patients the clinical findings depend on the number and location of cysticerci as well as the extent of surrounding inflammation. In the present case, we discuss an unusual presentation of the muscular cysticercosis as the cause of low back pain. The typical cysticercal cyst could be demonstrated on ultrasonography in the paraspinal muscles that responded well to conservative management.

Key words: Cysticercosis, diagnosis, high resolution sonography, intramuscular, medical management, noninvasive

\section{INTRODUCTION}

The blend of rural society, crowding, and poor sanitation creates more opportunities for fecal contamination of food and water thus leading to widespread tapeworm infection in developing countries. ${ }^{[1]}$ Taenia solium infection is common in latin American countries, Central and South Africa, India, Indonesia and China. ${ }^{[2]}$ Approximately 50 million people are infected with the parasite and some 50,000 die of cysticercosis annually. ${ }^{[3]}$ Cysticercosis is a parasitic infection caused by the larval stage (cysticercus) of T. solium. Humans can be the definitive host as well as the intermediate host of T. solium. Infection with the invasive intermediate stage (cysticercus) is called cysticercosis. The risk of cysticercosis may be the same for individuals who eat or do not eat pork, since humans acquire the intermediate form by ingestion of food or water contaminated with the eggs of T. solium. ${ }^{[4]}$ More often than not the patients with cysticercosis are asymptomatic and in symptomatic patients the clinical features depend on the number and location of cysticerci. In the present case, we discuss an unusual presentation of the muscular cysticercosis as the cause of low back pain.

\section{CASE REPORT}

An 20-year-old male presented with persistent low back ache of 2 months duration, which was localized to the lower back, non-radiating, without any difficulty in walking. There was no history of preceding trauma. Local examination of the spine and paraspinal region revealed an area of tenderness over the left side at the level of L2-L3 region. There was no local rise of temperature, or any palpable swelling. There was no history of hematuria in the past. Detailed neurological examination revealed no abnormality. Routine blood investigations were within normal limits. As a part of radiological work-up an ultrasonography (USG) abdomen was performed on Logiq 500 Pro machine (GE Medical Systems, USA) with a linear probe at $8.2 \mathrm{MHz}$ frequency. It revealed a well-defined isolated cystic lesion of size $1.8 \mathrm{~cm} \times 1.2 \mathrm{~cm}$ in the left paraspinal muscles with well-defined echogenic scolex of $3 \mathrm{~mm}$ size [Figure 1] with features of surrounding inflammation. These features were consistent with the diagnosis of cysticercosis in the lower paraspinal muscle. Ultrasound of the abdomen was normal. The patient was managed conservatively with a short course of tapering steroid, Prednisolone $2 \mathrm{mg} / \mathrm{kg} / \mathrm{day}$ and on the tablet albendazole $15 \mathrm{mg} / \mathrm{kg}$ body weight/day for 21 days. After 3 weeks of conservative treatment, on follow-up, pain and 


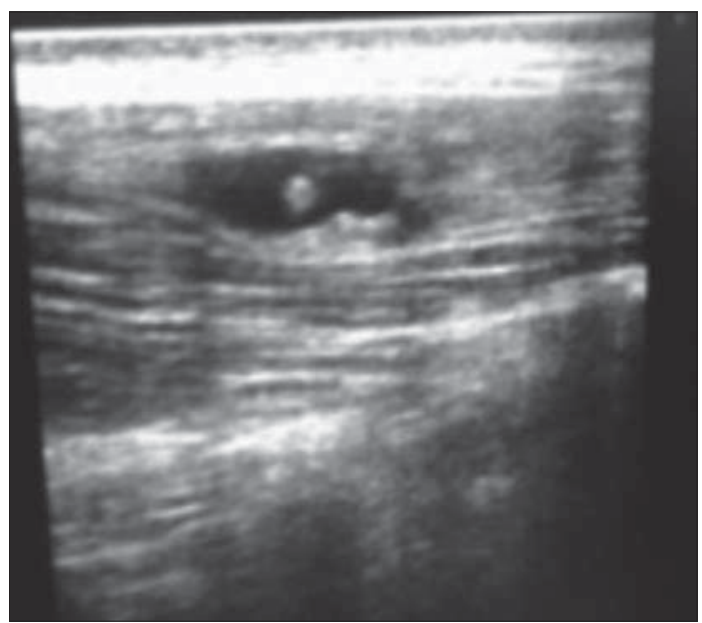

Figure 1: Isolated cystic lesion with well-defined echogenic scolex

tenderness completely disappeared and the patient was doing well. On follow-up USG, there was no evidence of cysticercosis. Patient was followed again after 3 months and he was relieved of his symptoms.

\section{DISCUSSION}

Although asymptomatic in the majority of the patients, the muscular form of cysticercosis can present clinically in three different ways myalgic, myopathic and nodular or mass like type (rarely pseudohypertrophy type). ${ }^{[5,6]}$ Many imaging modalities have been used to identify these lesions. ${ }^{[6]}$ Recently, high resolution sonography has been recognized as a safe and non-invasive method that can be used in the diagnosis of muscular and soft-tissue cysticercosis. ${ }^{[6,7]}$ On USG the muscular cysticercosisis characterized by a small, well-defined, elliptical cystic lesion with an eccentric hyperechoic area within, with or without surrounded inflammation and or calcification in the muscle. ${ }^{[7]}$ On USG four types of lesions have been described:

1. Cysticercus cyst with an inflammatory mass around it as a result of the death of the larva

2. An irregular cyst with very minimal fluid on one side, indicating a leakage of fluid. The eccentric echogenic protrusion from the wall due to the scolex is not seen within the cyst

3. A large irregular collection of exudative fluid within the muscle with the typical cysticercus cyst containing the scolex, situated eccentrically within the collection

4. Calcified cysticercosis. ${ }^{[7]}$

Solitary cysticercosis of muscles and soft tissue is a rare disease and can cause a diagnostic dilemma. ${ }^{[8]}$ Rarely, the paraspinal muscle involvement can be an incidental finding in a patient with low back because of other reasons. In the present case, the typical cysticercal cyst could be demonstrated on USG in the paraspinal muscles that responded well to conservative management.

\section{REFERENCES}

1. Ergen FB, Turkbey B, Kerimoglu U, Karaman K, Yorganc K, Saglam A. Solitary cysticercosis in the intermuscular area of the thigh: A rare and unusual pseudotumor with characteristic imaging findings. J Comput Assist Tomogr 2005;29:260-3.

2. Pawlowski ZS. Tapeworms (Cestodes). In: Schlossberg D, editor. Clinical Infectious Disease. New York: Cambridge University Press; 2008. p. 1359-63.

3. Juyal PD, Sharma R, Singh NK, Singh G. Epidemiology and control strategies against cysticercosis (due to Taenia solium) with special reference to swine and human in Asia. J Vet Anim Sci 2008;I: 1-10.

4. Blanton R. Cysticercosis. In: Kllegman RM, Stanton BF, Geme III JW, Schor NF, Behrman RE, editors. Nelson Textbook of Pediatrics. $19^{\text {th }}$ ed. Philadelphia PA: Saunders; 2011. p. 1234-7.

5. Mittal A, Sharma NS. Psoas muscle cysticercosis presenting as acute appendicitis. J Clin Ultrasound 2008;36:430-1.

6. Asrani A, Morani A. Primary sonographic diagnosis of disseminated muscular cysticercosis. J Ultrasound Med 2004;23:1245-8.

7. Vijayaraghavan SB. Sonographic appearances in cysticercosis. J Ultrasound Med 2004;23:423-7.

8. Jankharia BG, Chavhan GB, Krishnan P, Jankharia B. MRI and ultrasound in solitary muscular and soft tissue cysticercosis. Skeletal Radiol 2005;34:722-6.

How to cite this article: Afaq S, Mittal A, Mir RF. Isolated paraspinal muscle cysticercosis diagnosed on ultrasonography in a young patient presenting as low back ache. Int J Med Public Health 2013;3:211-2.

Source of Support: Nil, Conflict of Interest: None declared. 